\title{
Correction to: Both overlapping and independent loci underlie seed number per pod and seed weight in Brassica napus by comparative quantitative trait loci analysis
}

\author{
Shuangshuang Xin (D) Hongli Dong $\cdot$ Lei Yang $\cdot$ Dengwen Huang $\cdot$ Fajing Zheng $\cdot$ Yixin Cui $\cdot$ Shuang Wu \\ Jinghang Liao $\cdot$ Yajun He $\cdot$ Huafang Wan $\cdot$ Zhi Liu $\cdot$ Xiaorong Li $\cdot$ Wei Qian
}

Published online: 27 August 2021

(C) The Author(s), under exclusive licence to Springer Nature B.V. 2021

Correction to: Mol Breeding (2021) 41:41

https://doi.org/10.1007/s11032-021-01232-1

The original version of this article unfortunately contained incorrect Fig. 3b. The authors of this publication apologize for any inconvenience caused by this mistake. The corrected Fig. $3 b$ should be.
The original article can be found online at https://doi.org/ 10.1007/s11032-021-01232-1.

S. Xin $\cdot$ H. Dong $\cdot$ L. Yang $\cdot$ D. Huang $\cdot$ F. Zheng $\cdot$

Y. Cui - S. Wu · J. Liao · Y. He - H. Wan · Z. Liu · X. Li ·

W. Qian $(\bowtie)$

College of Agronomy and Biotechnology, Southwest

University, Chongqing 400715, China

e-mail: qianwei666@ hotmail.com

W. Qian

Engineering Research Center of South Upland Agriculture,

Ministry of Education, Chongqing 400715, China
Linkage disequilibrium analysis and haplotype analysis of 5 associated regions (a-e). Top, the horizontal axis represents haplotypes and the vertical axis represents the phenotypic values of 

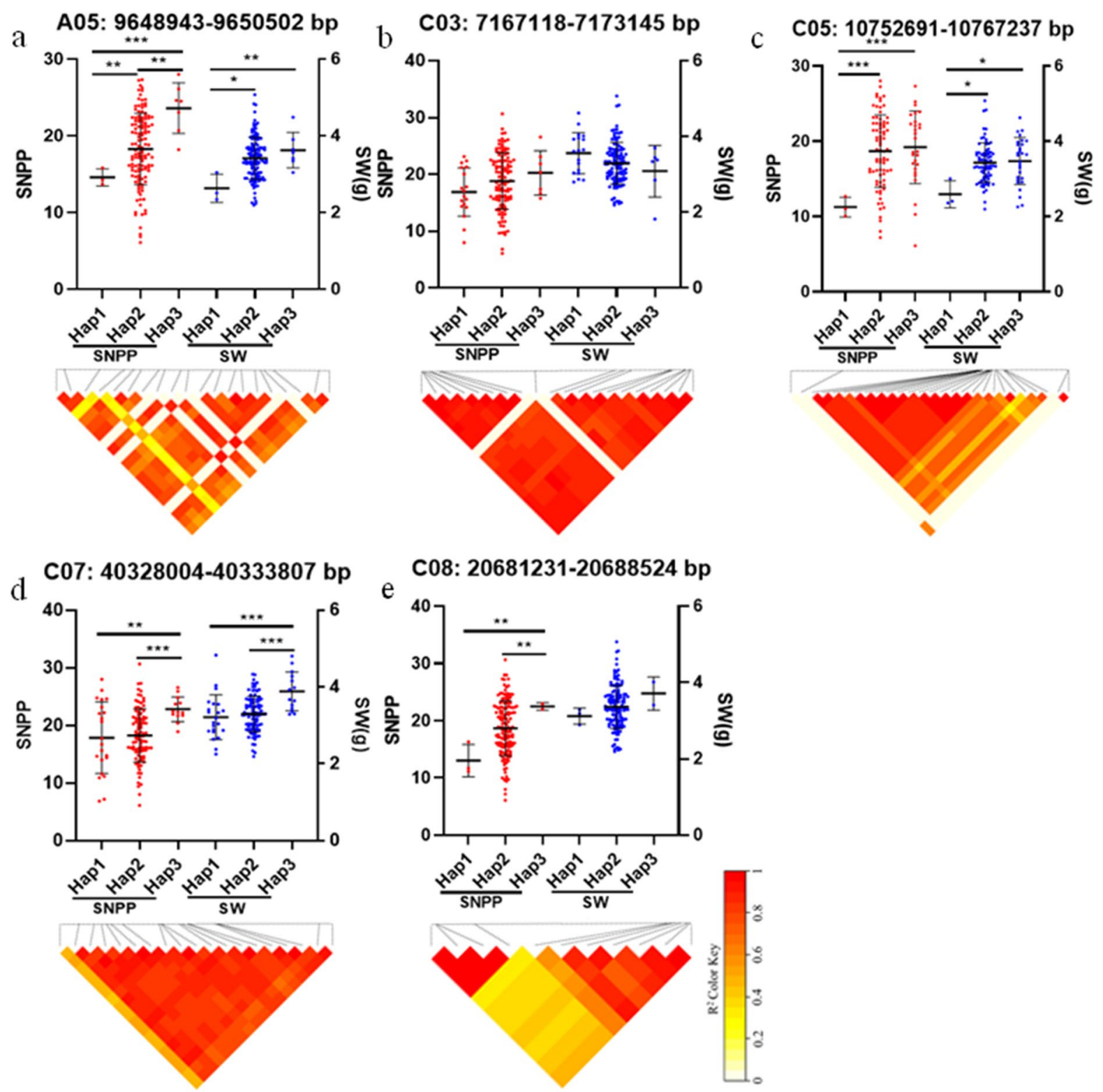

Fig. 3 Genetic effects on seed number per pod and seed weight among haplotypes in overlapping association regions in a natural population of rapeseed

seed number per pod and seed weight. The red and blue dots represent the average performance of SNPP and SW across years among 157 accessions in a natural population. $* * * * *, *$ : Signifcance at $P<0.001, P<0.01$, and $P<0.05$, respectively.
Bottom, pairwise LD estimates in the different haplotype blocks.

Publisher's note Springer Nature remains neutral with regard to jurisdictional claims in published maps and institutional affiliations. 